\title{
Evaluation of the Sedative Effect of Fragrance on Filipinas Using a Biochemical Marker
}

\author{
Masaki Yamaguchi ${ }^{1)}$, Josaku Sakakima ${ }^{1)}$, Kimiharu Sato ${ }^{2)}$ and Kimihiro Nakano ${ }^{2)}$ \\ 1) University of Toyama \\ 2) Procter \& Gamble Far East, Inc.
}

\begin{abstract}
The purpose of this study is to evaluate the usefulness of salivary amylase activity as an indicator of the acute psychological sedative effects of fragrances used in household products such as clothing softeners. Twenty seven healthy Philippine female subjects in their late $30 \mathrm{~s}$ were enrolled $(38.7 \pm 5.2 \mathrm{yr})$. This study was undertaken to investigate the favorite fragrance of Asian and Pacific Islander women. Our results indicated that (i) a mixed floral fragrance might be a favorite fragrance for Filipinas; (ii) fragrances contained in a softener significantly induced a sedative effect in humans, as assessed by both analysis of the biochemical marker and subjective evaluation; (iii) salivary amylase activity has the potential to be an excellent indicator for the evaluation of the acute psychological sedative effects of fragrance. $J$ Physiol Anthropol 26(2): 247-251, 2007 http:// www.jstage.jst.go.jp/browse/jpa2

[DOI: 10.2114/jpa2.26.247]
\end{abstract}

Keywords: biochemical marker, amylase, sympathetic nervous system, fragrance, sedative, Filipina

\section{Introduction}

Quantitative evaluation of the physiological effects of fragrance by conventional methods include subjective evaluations by questionnaire (Lundström et al., 2003) and physical measurements such as electroencephalogram (EEG) (Diego et al., 1998; Grosser et al., 2000), blood pressure (Haze et al., 2002), and heart rate (Romine et al., 1999). However, these physical measurements require the subjects to be physically restrained. Therefore, if an acute psychological effect of fragrance is to be quantified under field-based conditions rather than in a laboratory-based investigation, it is necessary to quantitatively measure the sedative state induced by them through subjective evaluation of emotions such as comfort and relaxation, so that the measurement method itself does not induce stress in the subjects.
In contrast, a biochemical method for the quantification of physiological effects has been investigated using a biochemical marker (biomarker) in saliva. Sampling saliva has the advantage that it is noninvasive, which makes multiple sampling easy, and does not introduce distress. Salivary amylase activity (sAMY) has been found to increase slightly with increased flow rates, and large increments in amylase concentration have been observed during sympathetic control by Speirs et al. (1974). sAMY can be a useful index of plasma norepinephrine concentration under a variety of stressful conditions, since it appears that increased sympathetic nervous activity is a major stimulator of amylase secretion (Jenkins 1978; Ugolev et al., 1979). Only Morse et al. reported that sAMY is increased during states of relaxation (1983). However, exercise (Nexo et al., 1988; Chatterton et al. 1996; Chicharro et al., 1998; Walsh et al., 1999) and psychological stressors (Bosch et al., 1996; Skosnik et al., 2000; Rohleder et al., 2004; Takai et al., 2004; Nater et al., 2005) are also able to stimulate salivary amylase. It has been suggested that salivary amylase may not only function as a digestive enzyme but may also have antibacterial action (Tanzer et al., 2001; Hannig et al., 2005). The antibacterial action may be one of the reasons why secretion of salivary amylase is increased by activation of the sympathetic nervous system.

The authors have been investigating an evaluation method based on a biomarker, sAMY (Yamaguchi et al., 2001). We have fabricated a hand-held type sAMY monitor which can be easily and quickly used for evaluating the activity of the sympathetic nervous system at any time (hand-held monitor; Yamaguchi et al., 2004; 2006). The time required for collection of saliva is approximately $10-30 \mathrm{~s}$, and it takes $30 \mathrm{~s}$ for analysis using the hand-held monitor; thus, a total of 1 minute is sufficient to analyse the sAMY.

The purpose of this study is to evaluate the usefulness of sAMY as an indicator of the acute psychological sedative effects of fragrances. The sample fragrances involved in this test require that their origins be known and that they contain no chemical materials that could directly activate the central 
nervous system. Thus, readily obtained clothing softeners, which meet the requirements, and have been prepared by perfumers for household products, were used as sample fragrances. Twenty seven healthy Philippine female subjects in their late $30 \mathrm{~s}$ were enrolled. This study was undertaken to investigate the favorite fragrance of Asian and Pacific Islander women. A Filipina is exposed to the fragrance of a softener by using a white towel washed in it. The time-course change in sAMY is quantitatively analysed using the hand-held monitor before and during the inhalation of fragrance. In parallel, subjective evaluations are conducted on each subject using a questionnaire. Finally, correlations between the biomarker analysis and the subjective evaluations are statistically evaluated.

\section{Materials and Methods}

\section{Subjects}

Twenty seven healthy Philippine female subjects were enrolled $(33-49 \mathrm{yr}, 38.7 \pm 5.2 \mathrm{yr})$ in this study. The study protocol was approved by the Ethical Committee of the Institutional Review Board of the University of Toyama, Medical Branch (Toyama, Japan). The study protocol was fully explained to all of the subjects in both spoken and written forms, specifically focusing on the purpose of the study, the precise procedures that would be used, and any possible adverse events. Signed informed consent was obtained from each subject who enrolled in the study.

\section{Procedures}

A hand-held SAMY monitor (hand-held monitor) had been previously fabricated by the authors (Yamaguchi et al., 2004; 2006). This hand-held monitor consists of a disposable teststrip and an optical analyzer $\left(126 \times 130 \times 48 \mathrm{~mm}^{3} ; 350 \mathrm{~g}\right)$, which is incorporated within an automatic saliva transcription device. The test-strip consists of a collecting sheet attached to the collecting papers, and a holder to which a reagent paper is attached. A volume of $20-30 \mu$ l of whole saliva is collected with the collecting paper placed under the tongue. When the test-strip is examined by the optical analyzer, the analysis is automatically controlled and the sAMY is shown on a display. This monitor was able to measure the environmental temperature at the same time as analyzing sAMY and automatically adjust the measured values into the sAMY at $37^{\circ} \mathrm{C}$. A coefficient of multiple determination of $R^{2}=0.98$ was obtained in a range between 0 and $140 \mathrm{kU} / 1$. The time required for collection of saliva was approximately $10-30 \mathrm{~s}$ for each subject, and it took $30 \mathrm{~s}$ for saliva transfer and analysis using the hand-held monitor; thus, a total of one minute was sufficient to measure the sAMY.

Subjective evaluation methods such as a profile of mood states (POMS, McNair and Lorr, 1964) and a state-trait anxiety inventory (STAI, Spielberger et al., 1970) have been used to measure the psychological effects. In order to measure the psychological sedative effect of fragrance, it is important to
Table 1 Chemical ingredients of the fragrance contained in softener.

\begin{tabular}{llr}
\hline \multicolumn{1}{c}{ Chemical ingredients } & Fragrance & CAS No. \\
\hline$\alpha$-Hexylcinnamaldehyde & Jasmine & $101-86-0$ \\
Geraniol & Rose & $106-24-1$ \\
3-(4-t-Butylphenyl)-2-isobutyraldehyde & Lily & $80-54-6$ \\
3-Ethoxy-4-hydroxybenzaldehyde & Vanillin & $121-32-4$ \\
\hline
\end{tabular}

decrease the number of questions on a questionnaire. A selfassessed questionnaire of psychological state (pre: $\mathrm{Q}_{1}$ and post: $\mathrm{Q}_{2}$ ) was set, consisting of six adjectives, relaxed, fun, anxious, refreshed, stressed, and uplifted, as a subjective evaluation. The applicability of the adjectives to current mood was marked by the subjects on a scale from one to five: strongly disagree (1), somewhat disagree (2), neither disagree nor agree (3), somewhat agree (4), or strongly agree (5).

\section{Study design}

A softener was used as the test sample of a household product which contained a mixture of four different floral fragrances, such as jasmine, rose, lily, and vanillin (Table 1). Each fragrance was prepared by a perfumer. The subjects were exposed to the mixed fragrance by using a white towel washed with a detergent and/or the softener. Three kinds of towel were used in this study as follows:

control: washed only with water,

study 1: washed with detergent without fragrance,

study 2: washed with detergent without fragrance, and also a softener with the mixed fragrance

In order to avoid the effects of the environment, the experiment was conducted in a small, partitioned area $\left(1.5 \times 3 \mathrm{~m}^{2}\right)$ of a quiet room where all visual stimuli were restricted and the temperature was maintained at around $25^{\circ} \mathrm{C}$. The humidity in the room remained within 44-65\% during the study. This experiment took place between 16:00 and 20:00 hrs. Prior to the experiment, the subjects were kept in nonsmoking conditions for the whole of the previous day. Moreover, subjects were not allowed to take any food or drink, except for water, for $1 \mathrm{hr}$ prior to the experiment. In order to clean the oral cavity, the subjects brushed their teeth clean and rinsed their mouths. Subjects then answered the questions identified in the questionnaire regarding their psychological state $\left(\mathrm{Q}_{1}\right)$.

Figure 1 shows the protocol used to evaluate the acute sedative effect of the mixed fragrance. Saliva sampling was performed at even intervals for the analysis of sAMY using the hand-held monitor, and repeated 5 times in total $\left(A_{1}-A_{5}\right)$. Initially, subjects took a sitting position for $3 \mathrm{~min}$ in order to measure their individual baseline of sAMY (baseline period, $A_{1}-A_{2}$ ). Next, the subjects held a white towel over their faces for 9 minutes to inhale the mixed fragrance (inhalation period, $\mathrm{A}_{3}-\mathrm{A}_{5}$ ). Immediately after completion of the mixed fragrance inhalation, the subjects filled in the psychological state questionnaire again $\left(\mathrm{Q}_{2}\right)$. The values of post-score minus pre- 


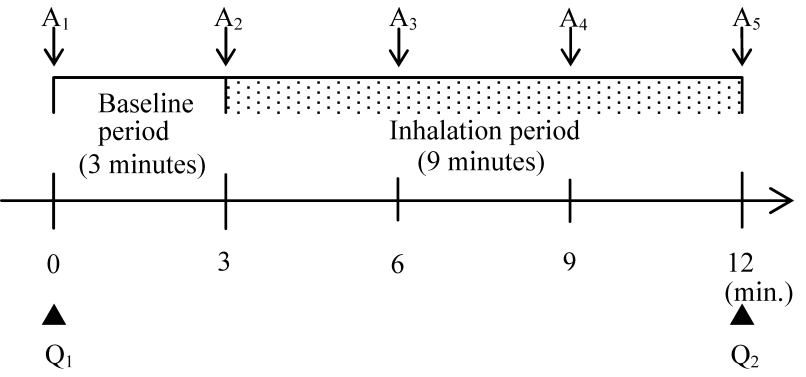

Fig. 1 Protocol in order to evaluate the acute sedative effect of fragrance. A1-5, analysis of SAMY; Q1-2, questionnaire of psychological states.

score $\left(\mathrm{Q}_{2}-\mathrm{Q}_{1}\right)$ were calculated for the 6 adjectives of the psychological state questionnaire.

\section{Statistical analysis}

Parametric tests were used as appropriate (SPSS 14.0J, SPSS Japan Inc., Japan). Within-group comparisons were performed using a paired Student $t$ test. Comparisons between groups were performed using an unpaired Student $t$ test. A value of $P<0.05$ was taken to represent statistical significance. Unless otherwise stated, all data are expressed as mean \pm standard deviation (SD).

\section{Results}

There were 7 subjects whose sAMY between baseline period levels $\left(A_{1}\right.$ and $\left.A_{2}\right)$ were changed by more than $\pm 15 \%$ in the control experiment. One explanation for this phenomenon may be that the environmental condition of temperature, humidity, and ventilation by the air-conditioner were not perfectly controlled. Therefore, the subjects were screened for greater than $\pm 15 \%$ changes, and the sAMY was compared in the remaining twenty subjects $(33-49 \mathrm{yr}, 38.3 \pm 5.7 \mathrm{yr})$ whose sAMY changed less than $\pm 15 \%$ during the baseline period in the control experiment.

Figure 2 shows the time-course changes of the sAMY in the control, study 1, and study 2 in twenty subjects. Comparison of the sAMY in the controls between $\mathrm{A}_{1}$ and $\mathrm{A}_{5}$ were 20.6 \pm 11.7 , $19.2 \pm 7.6,18.1 \pm 9.0,16.2 \pm 8.8$, and $18.7 \pm 9.9 \mathrm{kU} / 1$. There was no significant difference in salivary amylase activities between them. The sAMY in the baseline period $\left(\mathrm{A}_{1}-\mathrm{A}_{2}\right)$ of the control, study 1 , and study 2 ranged from $6-50,8-93$, and $8-69 \mathrm{kU} / 1$, respectively. The sAMY in the inhalation period $\left(\mathrm{A}_{3}-\mathrm{A}_{5}\right)$ of the control, study 1 , and study 2 ranged from $7-46,7-84$, and $8-56 \mathrm{kU} / 1$, respectively.

Table 2 shows the comparison of parametric tests between sAMY, $\mathrm{A}_{1}-\mathrm{A}_{5}$, using the paired Student $t$ test. The parametric tests of control, study 1 , and study 2 were independently calculated. There was no significant difference between baseline period $\left(A_{1}-A_{2}\right)$ and inhalation period $\left(A_{3}-A_{5}\right)$ in both the control and study 1 . On the other hand, in study 2 , the timecourse changes of SAMY decreased during the inhalation

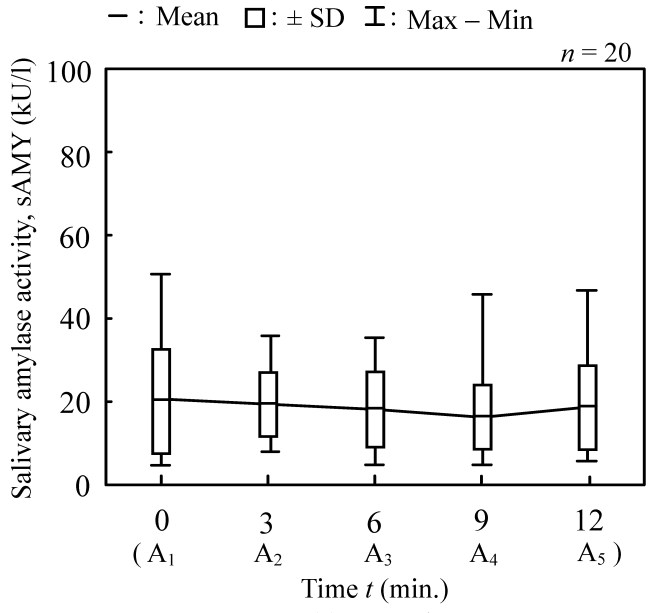

(a) Control

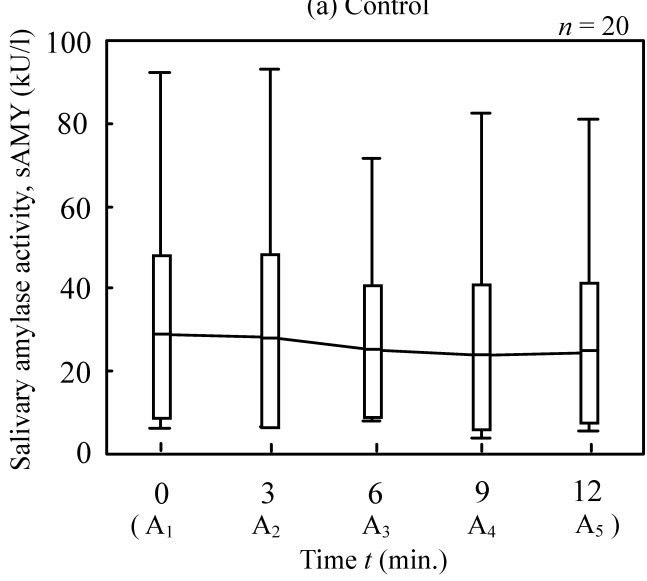

(b) Study 1



(c) Study 2

Fig. 2 Time-course changes of the sAMY in the control, study 1, and study 2 in 20 subjects.

period, and were significantly reduced compared with the baseline period $(P<0.05)$.

In the control, the scores of $\mathrm{Q}_{2}-\mathrm{Q}_{1}$ were $0.05 \pm 0.89$, $0.10 \pm 0.79, \quad 0.00 \pm 1.30, \quad 0.10 \pm 0.64, \quad-0.05 \pm 1.10, \quad$ and $0.05 \pm 0.69$, respectively (Fig. 3). No significant trend was observed in the six adjectives. On the other hand, in study 2 , it was observed that relaxed tended to increase, whilst anxious 
Table 2 Comparison of parametric test between sAMY, $\mathrm{A}_{1}-\mathrm{A}_{5}$, using paired Student $t$ test $(n=20)$

Control or Study 1

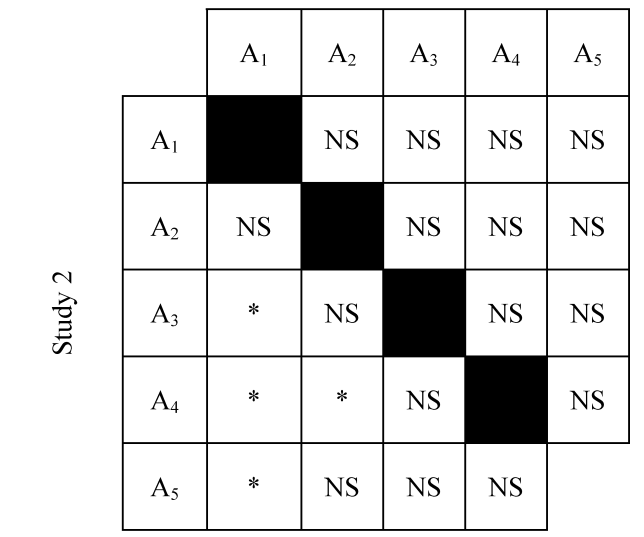

$*: P<0.05$, NS: not significant $(P>0.05)$

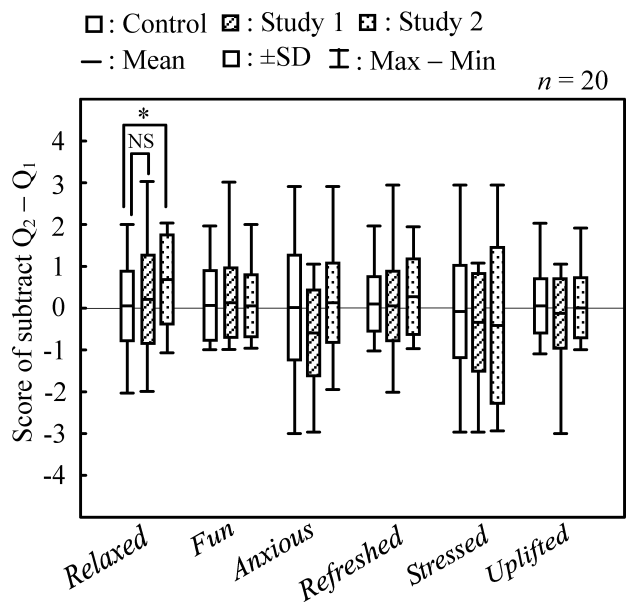

Fig. 3 Score of subtraction: pre-questionaire, Q1, from postquestionnaire, Q2. The applicability of 6 adjectives was marked on a scale of 5 from strongly disagree (1) to strongly agree (5). Withinadjective group comparison was performed using an unpaired student $t$ test. *: $P<0.05$, NS: not significant $(P>0.05)$.

and stressed kept constant when it was evaluated using the unpaired Student $t$ test. The skewness $\left(b_{1}\right)$ and kurtosis $\left(b_{2}\right)$ revealed that the scores of relaxed show a normal distribution $(P=0.01)$.

\section{Discussion}

In order to evaluate the usefulness of sAMY as an indicator of the acute psychological sedative effects of the mixed fragrance used in softeners, the time-course change in sAMY was examined before and during the inhalation of fragrance. In the subjective evaluations, a trend was observed that inhalation of test samples increased relaxed. It was considered that a mixed floral fragrance such as jasmine, rose, lily, and vanillin was a favorite fragrance for Filipinas.

Previously, it has been reported that the sAMY ranges are between 5 and $1,140 \mathrm{kU} / 1$ in humans (Tenovuo, 1989; Chatterton et al., 1996; Walsh et al., 1999; Yamaguchi et al. 2004; 2006; Nater et al., 2006). Since the sAMY during the baseline period was shown as 6-93 kU/1, it was considered that sympathetic nervous activity at the beginning of this test was relatively inactive. There was no significant difference in sAMY between baseline period $\left(\mathrm{A}_{1}-\mathrm{A}_{2}\right)$ and inhalation period $\left(A_{3}-A_{5}\right)$ in both the control and study 1 , whilst the inhalation period sAMY was significantly decreased in study 2 . Thus, it was revealed by both subjective evaluations and sympathetic nervous activity measurement that the mixed fragrance contained in softeners might induce sedative effects in humans. sAMY has the potential to be an excellent indicator for the evaluation of psychological sedative effects.

Saliva sampling may enable the simultaneous and noninvasive analysis not only of sympathetic nervous activity through amylase but also of several biomarkers of the endocrine and immune systems as well as neurotransmitters. If simultaneous and real-time analysis of multiple biomarkers can be developed, this would be a further useful tool as a fieldbased evaluation of products containing fragrances.

Acknowledgements A part of this research was supported by a Research Project for Utilizing Advanced Technologies in Agriculture, Forestry and Fisheries (Elucidation of physiological effects by elements of the forest environment, FY 2004-2006), Japan and Grants-in-Aid for Scientific Research C from the Japan Society for the Promotion of Science (No. 17500350, FY 2005-2006), Japan.

\section{References}

Bosch JA, Brand HS, Ligtenberg TJ, Bermond B, Hoogstraten J, Nieuw Amerongen AV (1996) Psychological stress as a determinant of protein levels and salivary-induced aggregation of Streptococcus gordonii in human whole saliva. Psychosom Med 58: 374-382

Chatterton TR, Vogelsong MK, Lu Y, Ellman BA, Hudgens AG (1996) Salivary $\alpha$-amylase as a measure of endogenous adrenergic activity. Clin Physiol 16: 433-448

Chicharro JL, Lucia A, Perez M, Vaquero AF, Urena R (1998) Saliva composition and exercise. Sports Med 26: 17-27

Diego MA, Jones NA, Field T, Hernandez-Reif M, Schanberg S, Kuhn C, Mcadam V, Galamaga R, Galamaga M (1998) Aromatherapy positively affects mood, EEG patterns of alertness and math computations. Int $\mathrm{J}$ Neurosci 96: 217-224

Grosser BI, Monti-Bloch L, Jennings-White C, Berliner DL (2000) Behavioral and electrophysiological effects of androstadienone, a human pheromone. Psychoneuroendocrinolo 25: 289-299

Hannig C, Hannig M, Attin T (2005) Enzymes in the acquired enamel pellicle. Eur J Oral Sci 113: 2-13

Haze S, Sakai K, Gozu Y (2002) Effects of fragrance inhalation on sympathetic activity in normal adults. Jpn J 
Pharmacol 90: 247-253

Jenkins GN (1978) The physiology and biochemistry of the mouth. Fourth Edition, Blackwell Scientific Publications, Oxford, 284-359

Lundström JN, Goncalves M, Esteves F, Olsson MJ (2003) Psychological effects of subthreshold exposure to the putative human pheromones 4,16-androstadien-3-one. Horm Behav 44: 395-401

McNair DM, Lorr M (1964) An analysis of mood in neurotics. J Abnormal and Social Psychol 69: 620-662

Morse DR, Schacterle GR, Furst ML, Esposito JV, Zaydenburg M (1983) Stress, relaxation and saliva: relationship to dental caries and its prevention, with a literature review. Ann Dent 42: 47-54

Nater UM, Rohleder N, Gaab J, Berger S, Jud A, Kirschbaum C, Ehlert U (2005) Human salivary alpha-amylase reactivity in a psychosocial stress paradigm. Int J Psychophysiol 55: 333-342

Nater UM, Rohleder N, Florin L, Moses A, Langhans W, Koller MM, Ehlert U (2006) Stress-induced changes in human salivary alpha-amylase activity - associations with adrenergic activity. Psychoneuroendocrinology 31: 49-58

Nexo E, Hansen MR, Konradsen L (1988) Human salivary epidermal growth factor, haptocorrin and amylase before and after prolonged exercise. Scand J Clin Lab Invest 48: 269-273

Rohleder N, Nater UM, Wolf JM, Ehlert U, Kirschbaum C (2004) Psychosocial stress-induced activation of salivary alpha-amylase: an indicator of sympathetic activity? Ann N Y Acad Sci 1032: 258-263

Romine IJ, Bush AM, Geist CR (1999) Lavender aromatherapy in recovery from exercise. Percept Motor Skill 88: 756-758

Skosnik DP, Chatterton TR, Swisher T, Park S (2000) Modulation of attentional inhibition by norepinephrine and cortisol after psychological stress. Int J Psychophysiol 36: 59-68

Speirs RL, Herring J, Cooper WD, Hardy CC, Hind CR (1974) The influence of sympathetic activity and isoprenaline on the secretion of amylase from the human parotid gland. Arch Oral Biol 19: 747-752

Spielberger CD, Goursh R, Lushene R (1970) Manual for the state-trait anxiety inventory. Consulting Psychologists Press,
California, 1-24

Takai N, Yamaguchi M, Aragaki T, Eto K, Uchihashi K, Nishikawa Y (2004) Effect of psychological stress on the salivary cortisol and amylase levels in healthy young adults. Arch Oral Biol 49: 963-968

Tanzer JM, Baranowski LK, Rogers JD, Haase EM, Scannapieco FA (2001) Oral colonization and cariogenicity of Streptococcus gordonii in specific pathogen-free TAN : SPFOM(OM)BR rats consuming starch or sucrose diets. Arch Oral Biol 46: 323-333

Tenovuo JO eds (1989) Human Saliva: Clinical Chemistry and Microbiology, Volume II. CRC Press Inc., Florida, 93-119

Ugolev AM, De Laey P, Iezuitova NN, Rakhimov KR, Timofeeva NM, Stepanova AT (1979) Membrane digestion and nutrient assimilation in early development. Ciba Found Symp 16-18: 221-246

Walsh NP, Blannin AK, Clark AM, Cook L, Robson PJ, Gleeson M (1999) The effects of high-intensity intermittent exercise on saliva IgA, total protein and $\alpha$-amylase. J Sport Sci 17: 129-134

Yamaguchi M, Kanemori T, Kanemaru M, Mizuno Y, Yoshida H (2001) Correlation of stress and salivary amylase activity. Jpn J Med Electron Biol Eng 39: 234-239

Yamaguchi M, Kanemori T, Kanemaru M, Takai N, Mizuno Y, Yoshida H (2004) Performance evaluation of salivary amylase activity monitor. Biosens Bioelectron 20: 491-497

Yamaguchi M, Deguchi M, Wakasugi J, Takai N, Higashi T, Mizuno Y (2006) Hand-held monitor of the sympathetic nervous system using salivary amylase activity and driver fatigue assessment. Biosens Bioelectron 21: 1007-1014

This article was presented at the 8th International Congress of Physiological Anthropology, 2006 (ICPA 2006), in Kamakura, Japan.

Received: August 28, 2006

Accepted: December 6, 2006

Correspondence to: Masaki Yamaguchi, Graduate School of Science and Engineering for Research, University of Toyama, 3190 Gofuku, Toyama 930-8555, Japan

Phone \& Fax: +81-76-445-6855

e-mail: yamag@eng.u-toyama.ac.jp 